\title{
EXPLORE FOREIGN LANGUAGE LEARNERS' EXPERIENCES UNDER A METACOGNITIVE LISTENING WEBSITE
}

\author{
Tao Pei ${ }^{1}$ and Jitpanat Suwanthep ${ }^{2}$ \\ ${ }^{I}$ Tongling University, Tongling, Anhui, China \\ ${ }^{2}$ Suranaree University of Technology, Nakhon Ratchasima, Thailand
}

\begin{abstract}
This study aimed to explore Chinese English as Foreign Language (EFL) learners' experiences in a metacognitive listening website based on a metacognitive approach. 40 Chinese low-intermediate EFL learners participated in the study and conducted the web-based metacognitive listening practice for 14 weeks. The UEQ and post-interview were used to detect their experiences and perceptions of the practice. The results indicated that these learners had good experiences with the metacognitive listening practice, especially in terms of dependability, novelty, and stimulation. The good experiences may be due to their perceived development of listening comprehension, listening strategies, and the involvement of video listening materials. However, learners' favouring test-based listening practice may affect their perceived efficiency of metacognitive listening practice. This study could provide a sample for further investigation of metacognitive intervention with CALL.
\end{abstract}

\section{KEYWORDS}

Listening Comprehension, Metacognitive Listening, User Experience, Web-Based Learning

\section{INTRODUCTION}

Recent years have seen increased attention on metacognitive instruction in second/foreign language listening research. Metacognitive instruction was vaguely defined in second language (L2) listening research and entangled with the strategy instruction (Cross, 2015). Cross (2015) unravelled the differences by pinpointing that metacognitive instruction aimed to develop the metacognitive knowledge and listening strategies, as opposed to the strategy instruction that mainly emphasized developing strategy use. Thus, designing metacognitive instruction should involve reflective activities that could elicit learners' thinking on their metacognitive knowledge (Goh, 2008). Vandergrift $(2004,2007)$ ever proposed a pedagogical cycle —as a typical metacognitive listening model (Cross, 2015) - involved learners through metacognitive processes of listening and peer discussion and reflection. In this way, the cycle could increase listeners' metacognitive knowledge and orchestration of the deployment of listening strategies. Many studies (e.g., Bozorgian \& Alamdari, 2018; Vandergrift \& Tafaghodtari, 2010; Wang, 2016) have verified the effectiveness of this pedagogical cycle on L2 listeners' listening comprehension and metacognitive awareness in different contexts. On the other hand, e-learning has become a trend since the 1990s and offers learners more chance of monitoring and regulating their learning process (Prastiyo et al., 2018; Rodríguez-Ardura \& Meseguer-Artola, 2015). However, although substantial studies investigated the metacognitive listening training inside the classroom, rare research tackled how to implement the metacognitive approach in an online learning environment.

In terms of ISO 9241-11, user experience or usability means the "extent to which a system, product or service can be used by specified users to achieve specified goals with effectiveness, efficiency and satisfaction in a specified context of use" (International Organization for Standardization, 2018). Hassenzahll et al. (2000) indicated that the evaluation of user experience should capture two quality dimensions of a product: ergonomic quality and hedonic quality. Ergonomic quality (EQ) means "the usability of the product, which addresses the underlying human need for security and control" (Hassenzahl, 2001, p. 483) and is 
related to the task-oriented aspects of the product. A good EQ could make task implementation in a product effective and efficient. Hedonic quality (HQ) "refers to quality dimensions with no obvious - or at least a second-order-relation to task-related goals such as originality, innovativeness, and so forth" (p. 483). HQ deals with users' needs for "novelty or change and social power (status) induced, for example, by visual design, sound design, novel interaction techniques, or novel functionality" (p. 483). By combining the two qualities, users could shape an overall judgment of the product attractiveness.

Hassenzahl et al. (2000) further indicated that the appraisal of the user experience induced two consequences. One is the behavioural consequences, such as the increased or decreased usage frequency and time, and the quality of work results. The second is the emotional consequences of the increased or decreased enjoyment, interest, and satisfaction. From this, the user experience appraisal may impact learners' engagement, performance, and motivation in web-based listening. Given the importance of user experience, this study explored second language learners' experiences in web-based metacognitive listening practice.

\section{METHODOLOGY}

\subsection{Settings and Participants}

The study recruited 40 EFL learners from first-year students from a Chinese university with 33 females and 7 males, ranging from 18 - 22 years old. The TOEFL scores before treatment indicated that they were low proficient listeners. Most of them had formal English of 12 years, and none had learning experiences in English as native language countries. All of them admitted they were regular internet users with mobile phones or computers.

\subsection{Design of Metacognitive Listening Website}

There are 28 sets of listening practice on the metacognitive listening website. Each set of listening practice is constructed based on metacognitive instruction cycle (Vandergrift, 2004, 2007) and aims to lead learners through the metacognitive processes of listening comprehension. Also, since previous researchers (Cross, 2011; Goh, 2008; Graham \& Santos, 2015; Vandergrift \& Tafaghodtari, 2010) have called for the inclusion of bottom-up listening training into the latter stages of Vandergrift's cycle to enhance its effectiveness, we added the sentential dictation tasks (as the bottom-up practice) in the third listening stage of the listening practice. The steps of each listening practice are shown in Table 1.

Table 1. Stages of the online metacognitive listening practice

\begin{tabular}{|c|c|}
\hline Stages & Metacognitive processes \\
\hline \multicolumn{2}{|l|}{ 1.Pre-listening-Planning/predicting stage } \\
\hline $\begin{array}{l}\text { Learners were informed of the topic, related words, and text type of the listening } \\
\text { material. Then they answered some questions to plan their listening goals, strategy } \\
\text { use, and potential listening problems, and make predictions of information and } \\
\text { possible words. }\end{array}$ & $\begin{array}{l}\text { Planning strategy; } \\
\text { person, task, and strategy knowledge. }\end{array}$ \\
\hline \multicolumn{2}{|l|}{ 2. First Listening_First Verification Stage } \\
\hline \multicolumn{2}{|l|}{ 3. Second Listening-Second Verification Stage } \\
\hline $\begin{array}{l}\text { Learners verified listening again, supplemented the missing information in the first } \\
\text { listening, and then evaluated the effectiveness of listening strategies for the second } \\
\text { listening and the degrees of comprehension. They could choose to listen again if } \\
\text { they had perceived the low degrees of comprehension of the video clip. Then they } \\
\text { answered two or three listening comprehension questions and summarized the main } \\
\text { contents of the listening text. After completion, they checked the answers. }\end{array}$ & $\begin{array}{l}\text { Monitoring, evaluation, and problem-solving } \\
\text { strategies; } \\
\text { person and strategy knowledge }\end{array}$ \\
\hline
\end{tabular}


4. Third Listening - Final Verification Stage

Learners completed the sentential dictation tasks and checked the transcripts. Then, they wrote the difficult words during listening and evaluated the difficulty level of the listening materials and their general performance.

5. Reflection Stage

Learners summarized listening problems and useful strategies in the listening process and plan strategies for next listening. evaluation and problem-solving strategies task and person knowledge.

Evaluation and problem-solving strategies; person, task, and strategy knowledge.

\subsection{Research Design and Instruments}

The study adopted a mixed method design. The mixed method design used a quasi-experimental one-group posttest and the qualitative methods of interviews. The learners' experience was examined with UEQ (User Experience Questionnaire) and the post-semi-interview. Both instruments were administered after learners practised listening on the website for 14 weeks. UEQ was constructed and validated by Laugwitz et al. (2008). UEQ was built based on Hassenzahl's (2001) model of user experience. Under the model, users' perceived ergonomic and hedonic quality could reflect the assessment of the appealingness towards the target product. The target product in the study was the listening website. UEQ was composed of six scales under three dimensions. The six scales were attractiveness, perspicuity, efficiency, dependability, stimulation, and novelty: attractiveness means users' overall impression of the product; perspicuity means the extent to which the product was easy to use; efficiency means the extent to which the tasks could be solved without unnecessary efforts; dependability means the extent to which the product is dependable and predictable, and could achieve the expected goal; stimulation means the extent to which the product is motivating and exciting; novelty means the extent to which the product is innovative and engage the users. Among these, attractiveness represented the overall impression of the product; perspicuity, efficiency, and dependability represent the ergonomic quality dimension; and stimulation and novelty were under the hedonic quality dimension. Laugwitz et al. (2008) validated the UEQ in several studies with participants in Germany and the USA, which showed that the reliability of UEQ was above the acceptable level on each scale, with the coefficient $\alpha>$.60. The researcher translated UEQ into Chinese and piloted it with four listeners to reduce their misinterpretation of each item. The reliability for the translated UEQ in the study was above the acceptable level, with the coefficient $\alpha=.88$. Also, the first researcher conducted a semi-interview to elicit learners' responses on their perceptions of listening practice under the website. 19 learners were randomly selected to join in the post-interview with their consent. This number reached that of gaining saturation $(\mathrm{N}=12)$ in interviews by Guest et al. (2006). The interviews lasted about 10 minutes for each participant.

\subsection{Procedures}

The whole experiment lasted 15 weeks. Before engaging in the practice, they received a 90 -minute training by the researcher to know how to conduct the web-based listening practice. For 14 weeks, learners completed two sets of listening practice on the website each week with computers or mobile phones. The first researcher checked learners' responses in the listening practice and reminded those learners who failed to complete the listening practice each week. Learners were informed to contact the researcher through the QQ at any time if they had problems or difficulties in the listening process. They could also choose to browse over other content on the website. In the $15^{\text {th }}$ week, learners took UEQ and 19 learners were randomly selected to receive semi-interviews by the first researcher.

\subsection{Data Analysis}

The data from UEQ were analysed with the data analysis tool on the UEQ website (https://www.ueq-online.org/). The data analysis tool also made possible the comparison with the benchmark that contains data from 18483 persons of 401 studies concerning different internet-related products (business software, web pages, web-shops, social networks), to assess the "goodness" of user experience. Interview data were transcribed verbatim and firstly coded by the first researcher to observe the emergent themes. Another researcher helped recode the interview data again with the original themes. After negotiation, we reached the final themes by controlling the percentage of agreement at $90 \%$, a good indicator for the inter-rater reliability. 


\section{RESULTS}

\subsection{Results from the UEQ}

To detect learners' experiences of the website, the researcher conducted the descriptive statistics to observe the mean scores and standard deviations of each dimension in UEQ, as shown in Table 2.

Table 2. Descriptive statistics of means and standard deviations

\begin{tabular}{llll}
\hline Scales & Mean & SD & N \\
\hline Attractiveness & 1.88 & 0.86 & 40 \\
Perspicuity & 1.57 & 0.90 & 40 \\
Efficiency & 1.64 & 0.82 & 40 \\
Dependability & 1.81 & 0.83 & 40 \\
Stimulation & 1.84 & 0.87 & 40 \\
Novelty & 1.96 & 0.88 & 40 \\
\hline
\end{tabular}

Table 2 shows that the learners performed a positive evaluation on all scales in UEQ, indicating good experiences to work with the metacognitive listening website. Meanwhile, learners had a general better evaluation of the hedonic quality than the ergonomic quality of the website.

In order to generate a more reliable evaluation and detect whether the web-based metacognitive listening practice could fulfill users' general expectations (Schrepp, Hinderks, \& Thomaschewski, 2017), the data analysis tool of the UEQ authors also provided the analysis of comparing the mean scores with a benchmark containing the evaluation of a large sample of data, shown in Table 3.

Table 3. Comparison of the means of user experience to the benchmark

\begin{tabular}{llll}
\hline Scale & Mean & Rank & Interpretation \\
\hline Attractiveness & 1.88 & Excellent & In the range of the $10 \%$ best results \\
Perspicuity & 1.57 & Good & Less than $25 \%$, better than $50 \%$ of results \\
Efficiency & 1.64 & Good & Worse than $10 \%$, better than $75 \%$ of results \\
Dependability & 1.81 & Excellent & In the range of the $10 \%$ best results \\
Stimulation & 1.84 & Excellent & In the range of the $10 \%$ best results \\
Novelty & 1.96 & Excellent & In the range of the $10 \%$ best results \\
\hline
\end{tabular}

Learners' responses in 4 dimensions from UEQ were excellent (among the $10 \%$ best results) and 2 were good (better than 50\% results) compared with benchmark data, indicating that learners had positive feelings towards the metacognitive listening website. Specifically, learners' experience of the listening website was excellent regarding attractiveness and the hedonic quality, suggesting that these listeners felt attracted by the web-based listening, especially impressed by the innovative design and much motivated by this kind of listening practice. Meanwhile, the high score in dependability, one of the ergonomic quality, also revealed the learners' tenacious belief that they could rely on the online listening practice to improve their listening comprehension ability. Also, scores on the other two dimensions of ergonomic quality - perspicuity, and efficiency - represented that the learners were still satisfied with the conciseness and efficiency of the online listening practice.

\subsection{Results from the Interview Results}

To ensure confidentiality, the researchers used the name codes (S plus the number, e.g., S1, S2) for interviewees in the following data presentation.

\subsubsection{Improvement of Listening Comprehension Ability}

Most learners reported notable improvement of listening comprehension ability, as illustrated in Excerpt 1.

Excerpt 1:

While listening, I could get a more logical understanding than before. (S3)

I got improved in filling the blank, listening to numbers, and answer the listening 
comprehension questions. (S10)

I became more patient since I could endure two-hour listening practice one time. (S11)

I got improved in listening ability...I have been in a better state during listening than before.

(S12)

Excerpt 1 indicates that these learners gained more understanding, better listening state, more patience, and more success in completing listening tasks. Their perceived improvement in listening could be due to the effectiveness of the metacognitive listening approach in the website and also could be reflected by the high dependability in UEQ, denoting that these learners felt the listening practice was dependable to achieve their listening goals.

\subsubsection{Good Experiences}

Most learners used "quite good" to evaluate the metacognitive listening practice, suggesting their affirmation of attractiveness in UEQ - a general evaluation of the website. Some learners pointed out the innovativeness of the listening website, as shown in Excerpt 2.

Excerpt 2:

The listening website is quite good and innovative. Before, we just listened to the audio. (S9) It [the listening website] is quite good, and the form of practice is quite innovative...the website has the predictions before listening and videos, not merely the multiple-choice as the test. (S18)

\subsubsection{Preferences}

\section{Preference for the metacognitive listening practice}

Some learners reported the preference for metacognitive listening practice to the test-based listening practice. Some of them indicated more fun and closeness to life of the listening practice, possibly owing to the appearance of videos, as seen from the Excerpt 4.

\section{Excerpt 4}

This kind of listening practice asked us to extract some information through prediction and verification after listening. In this case, we could grasp the whole meaning of the listening materials. (S5)

I preferred this kind of listening... I think this kind of listening was not formal...when in the test, I was very anxious. (S12)

um...I like this kind of listening; because I could watch videos and engage the ears and eyes into understanding. In traditional listening practice, only ears are involved. (S7)

From Excerpt 4, S12 perceived less anxiety in the web-based metacognitive listening practice; S7 indicated her enjoyment of the video contents; S5 suggested the benefits of undergoing the metacognitive listening process of planning (prediction), verification, and reflection on their listening comprehension.

\section{Choice phobia}

Some learners demonstrated their like or positive evaluation of the metacognitive listening practice but admitted that they had to practice the test-based listening, seen in the Excerpt 7.

Excerpt 7

I like this kind of listening practice because it provides intensive training for us. However, I must practice the test-based listening for getting scores from the test and practice the multiple-choice listening items. (S17)

I am personally interested in this kind of listening practice. But if you want to gain high scores

in tests, you must choose the traditional test-based listening. (S2)

From the above, these learners' positive evaluation could again confirm the high attractiveness and dependability in the UEQ. However, they still perceived the importance of listening tests and that the development of listening comprehension ability should be reflected in test scores. On account of the long-established test-oriented culture in China (Guo, Diaz, \& Liyanage, 2016; Hu \& West, 2015), language teachers and learners were highlighting the outcomes of tests as their main instructional or learning goals. Learners' emphasis on listening tests could also explain the relatively low efficiency in UEQ as they may deem that the website may not be as efficient in improving listening scores as the listening tests.

Besides the role of tests in their English learning, some learners indicated the test-based listening was more formal and rendered them more focused in Excerpt 8. 


\section{Excerpt 8:}

Both kinds of practice are ok for me... I think the test-based listening should be more formal. (S6)

I also like traditional test-based listening because I am easily distracted when practising listening after class. If I practised the listening tests, I would be more focused. (S13)

\section{Preference for the test-based listening practice}

Still some learners supported the test-based listening practice and indicated the importance of listening tests in gaining scores and concentration, as seen in Excerpt 9.

Excerpt 9:

I think the test-based listening is more systemic and has some questions I must answer. It is complete. It could help improve my listening scores. (S12)

The test-based listening could make a little nervous, and I could become more focused. From childhood, listening is always in the form of testing. In my spare time, I sometimes listen to news or music. (S19)

From the above, S12 indicated the systemic of tests and its role in improving listening scores, reflecting her idea that listening should produce some products like answering some questions; S14 and S19 indicated that the test-based listening could contribute to concentration, due to the formal atmosphere and some nervousness it produced. This is consistent with the view that mild anxiety could alert people to be more concentrated and improve performance in specific situations (Goleman, Boyatzis, \& McKee, 2013; Miller \& Stoeckel, 2019; Wiseman \& Hunt, 2013). S19 further indicated that for her, English listening mainly meant testing since the routine listening tasks came from the tests.

\subsubsection{Modification}

When asked about how to modify the website, many learners mentioned the overloaded questions in metacognitive listening practice to increase their metacognitive awareness, as seen in Excerpt 10.

\section{Excerpt 10:}

I think there should be fewer questions [about the planning, strategies, and problems] before listening. (S9)

Some repetitive questions, such as the prediction questions, appear three times for me to make prediction and verification. Maybe you could reduce some questions about these. (S10)

Every time the questions are the same. These questions [about listening problems] should appear after four or five weeks because listening problems of today and tomorrow are usually the same, and they don't change so quickly. (S12)

These appeals for less questions could reflect the redundancy in the listening practice, which resulted in relatively low scores in the perspicuity and efficiency of UEQ.

Still, some learners suggested the addition of dictation exercises and categorization of listening topics, shown in Excerpt 12.

\section{Excerpt 12:}

Maybe you could classify the listening tasks according to the topics of listening materials.

I think maybe you could categorise listening practice tasks and put together the listening materials with more connected speech (S12).

It is better to add some practice for the number of dictations or other dictation exercises. (S13)

You could add some dictation exercises. (S19)

S12 and S15 indicated the categorisation of listening tasks based on different criteria. S15 hoped for the grouping by the topics, possibly to increase listening motivation. S12 suggested the grouping by different types of "connected speech" and expected some improvement in this skill. S13 and S19 suggested the addition of dictation tasks, perhaps partly because the dictation tasks (e.g., the dictation of large numbers) were included in their textbooks and in the high-stake TEM-4 tests that these learners were required to pass for graduation. These learners' emphasis of dictation and connected speech could indicate that they longed for more practice of bottom-up listening skills in the online listening practice and the relations between the development of listening ability and bottom-up listening skills. 


\section{DISCUSSION}

The study indicated that the current low proficient L2 listeners had good experiences with the web-based metacognitive listening practice.

Regarding UEQ, four scales were at an excellent level, and two at a good level, suggesting this website arrived at the general user experience expectation (Schrepp et al., 2017). The positive evaluation of the listening website from the interview supported the high attractiveness revealed in the UEQ. Learners' high scores in dependability - suggesting that they have achieved predictable goals - could be reflected by their improvement in listening comprehension ability and the development of metacognitive knowledge and strategies. Learners' high scores in stimulation was confirmed by learners' "feeling interested and fun" in the listening practice. The involvement of videos and authentic listening materials could contribute to this feeling. Also, the "relaxing" environment with less anxiety could bring more motivation to engage in the listening website. The high novelty in the UEQ was predictable since the website contained many metacognitive listening activities, rendering it different from traditional comprehension-based listening websites. Learners also confirmed this in the interview, as some indicated that this listening practice could help develop listening strategies, different from the traditional test-based listening. The high scores in stimulation and novelty represents the high hedonic quality of the website, revealing learners' high satisfaction in using the website (Laugwitz et al., 2008). The other two ergonomic quality falls into the "good" level, suggesting some room for improvement. In the interview, some indicated they were overloaded with metacognitive questions, weakening their perceptions of the perspicuity and efficiency of the website. Meanwhile, perceived slowness of the website and concerns about the listening test results also reduced their perceived efficiency.

In the interviews, the current learners felt they could not abandon the test-based practice, and some test items such as dictation should be added. It also implied their emphasis on listening tests and bottom-up skill development. The focus on the test-based practice could be due to the influence of high-stake English tests in the Chinese context. These high-stake tests were of great importance not just for students to select the access to prestigious or commonplace higher institutions (Fang \& Warschauer, 2004), but for schools and individual teachers to earn praises and bonuses (Cortazzi \& Jin, 1996). Hence, "[language] teachers ... find it impossible to resist pressures that too frequently lead them to focus on test preparation" (Guo et al., 2016, p. 5). Emphasis on test results would transform the listening classes into a 'testing' rather than teaching" (Siegel, 2015, p. 40). It is of no doubt that learners in this context hope to practise listening tests, which for them, was a more efficient way to improve their listening comprehension.

\section{CONCLUSION}

This study attempted to examine the Chinese EFL low-intermediate learners' experiences of the website. In general, they had good experiences with the listening website, especially in terms of dependability, novelty, and stimulation. The follow-up interview indicated that their good experiences on these aspects could be due to their perceived development of listening comprehension ability, the novelty of the listening practice in developing listening strategies, and the involvement of authentic video listening materials. Still, some learners favoured the bottom-up listening training and the test-based listening practice, probably due to the test-based education environment in China and the ideology of language teachers.

Meanwhile, good experiences could yield positive emotions of learners and engage them more in the self-directed listening website, thus promoting the emergence of the desired outcomes of the metacognitive listening website. Also, the blended learning or flipped classroom could operate with the availability of the metacognitive listening website. There was evidence on the advantage of the web-based metacognitive listening practice over traditional comprehension-based online listening practice in developing listening comprehension ability. However, more evidence was still needed. No evidence was about whether the web-based metacognitive listening practice could exert better results in listening development than the metacognitive instruction inside the classroom. Besides, although many studies (e.g., Cross, 2011) pinpointed the benefits of metacognitive were confined to the less-skilled listeners, some researchers indicated that adding bottom-up listening training could allow the metacognitive listening approach to benefit even the skilled listeners. However, according to Yeldham $(2016,2018)$, intermediate listeners could gain more 
benefits from the top-down way of listening (e.g., strategy or metacognitive instruction) than the "bottom-up" way of listening (e.g., training of bottom-up skills). Thus, this is still open to question whether the training focus should switch to the bottom-up skills for the skilled listeners who already had a rich repertoire of metacognitive awareness.

\section{REFERENCES}

Bozorgian, H., \& Alamdari, E. F. (2018). Multimedia listening comprehension: Metacognitive instruction or metacognitive instruction through dialogic interaction. ReCALL, Vol. 30, No. 1, pp 131-152.

Cortazzi, M., \& Jin, L. (1996). Cultures of learning: Language classrooms in China. in H. Coleman (ed.) Society and the Language Classroom (pp159-206). Cambridge: CUP

Cross, J. (2011). Metacognitive instruction for helping less-skilled listeners. ELT Journal, Vol. 65, No. 4, pp. 408-416.

Cross, J. (2015). Metacognition in L2 listening: Clarifying instructional theory and practice. TESOL Quarterly, Vol. 49, No. 4, pp 883-892. https://doi.org/10.1002/tesq.258

Fang, X., \& Warschauer, M. (2004). Technology and curricular reform in China: A case study. TESOL Quarterly, Vol. 38, No. 2, pp 301-323.

Goh, C. C. (2008). Metacognitive instruction for second language listening development: Theory, practice, and research implications. RELC Journal, Vol. 39, No. 2, pp 188-213.

Guest, G., Bunce, A., \& Johnson, L. (2006). How many interviews are enough? An experiment with data saturation and variability. Field Methods, Vol. 18, No. 1, pp 59-82.

Guo, X., Diaz, A., \& Liyanage, I. (2016). Exploring the professional agency chasm in exam-driven English language education contexts. In H. V. Rensburg \& S. O'Neill (Eds.), Deep languages education policy and practices: Stimulating languages learning - global perspectives and local practice ( $\mathrm{pp}$ 215-232). Blue Mounds: Deep University Press.

Hassenzahl, M. (2001). The effect of perceived hedonic quality on product appealingness. International Journal of Human-Computer Interaction, Vol. 13, No. 4, pp 481-499.

Hassenzahl, M., Platz, A., Burmester, M., \& Lehner, K. (2000, April). Hedonic and ergonomic quality aspects determine a software's appeal. In Proceedings of the SIGCHI conference on Human Factors in Computing Systems (CHI '00). Association for Computing Machinery, New York, NY (pp 201-208).

International Organization for Standardization. (2018). Ergonomics of human-system interaction — Part 11: Usability: Definitions and concepts (ISO Standard No. 9241-11:2018).

Laugwitz, B., Held, T., \& Schrepp, M. (2008). Construction and Evaluation of a User Experience Questionnaire. In A. Holzinger (Ed.), HCI and Usability for Education and Work (pp 63-76). Berlin: Springer Berlin Heidelberg.

Prastiyo, W., Djohar, A., \& Purnawan, P. (2018). Development of YouTube integrated google classroom based e-learning media for the light-weight vehicle engineering vocational high school. Jurnal Pendidikan Vokasi, Vol. 8, No. 1, 53-66.

Rodríguez-Ardura, I., \& Meseguer-Artola, A. (2016). E-learning continuance: The impact of interactivity and the mediating role of imagery, presence and flow. Information \& Management, Vol. 53, No. 4, pp 504-516.

Schrepp, M., Hinderks, A., \& Thomaschewski, J. (2017). Construction of a Benchmark for the User Experience Questionnaire (UEQ). International Journal of Interactive Multimedia and Artificial Intelligence, Vol. 4, No. 4, pp 40-44.

Siegel, J. (2015). Exploring listening strategy instruction through action research. New York: Palgrave Macmillan.

Vandergrift, L. (2004). Listening to learn or learning to listen?. Annual Review of Applied Linguistics, Vol. 24, pp 3-25. http://doi.org/10.1017/S0267190504000017

Vandergrift, L. (2007). Recent development in second and foreign language listening comprehension research. Language Teaching, Vol. 40, No. 3, pp 191-210.

Vandergrift, L., \& Tafaghodtari, M. H. (2010). Teaching L2 learners how to listen does make a difference: An empirical study. Language Learning, Vol. 60, No. 2, pp 470-497.

Wang, W. (2016). Learning to listen: The impact of a metacognitive approach to listening instruction. The Asia-Pacific Education Researcher, Vol. 25, No. 1, pp 79-88.

Yeldham, M. (2016). Second language listening instruction: Comparing a strategies-based approach with an interactive, strategies/bottom-up skills approach. TESOL Quarterly, Vol. 50, No. 3, pp 394-420.

Yeldham, M. (2018). L2 listening instruction: More bottom-up or more top-down? Journal of Asia TEFL, Vol. 15, No. 3, pp 805-810. 